\title{
Practices of Preventing Coal and Gas Outburst through Water Injection in Coal Seam with Low Gas Permeability
}

\author{
Jufeng Zhang ${ }^{1,2, ~ a, ~ *, ~ R u i y u n ~ W a n g ~}{ }^{3, ~ b}$, Fengfeng Yang ${ }^{1}$, Lan Yu ${ }^{1}$, Rili Yang ${ }^{1}$, Jianjiang Zhang ${ }^{3}$, \\ Zaiquan Miao ${ }^{3}$ \\ ${ }^{1}$ College of Energy Engineering, Longdong University, Qingyang 745000, China \\ ${ }^{2}$ School of Resource, Environment and Safety Engineering, Hunan University of Science \\ and Technology, Xiangtan 411201, China \\ ${ }^{3}$ Weijiadi Coal Mine of Gansu Jingyuan Coal and Electricity Co., Ltd. Baiying 730913, China \\ ajufeng6100229@126.com,422622510@qq.com
}

Keywords: Outburst coal seam; long borehole static pressure water injection; short borehole hydrodynamic pressure water injection; anti-outburst effect

\begin{abstract}
In order to prevent effectively coal and gas outburst accidents in the mining process of the 1302 working face in the Weijiadi coal mine, adhere to strictly the principle of regional anti-outburst measures and supplement the principle of partial anti-outburst measures, and under the premise of regional anti-surge measures implementation, coal water injection was put forward to eliminate coal seam risk., that is a partial anti-outburst measure. On the basis of analyzing the mechanism of water injection and outburst prevention in coal seams, a water injection scheme for coal seams was developed, which combines hydrostatic pressure water injection for long boreholes in two-shaft drilling and dynamic pressure water injection for short-hole drilled holes on the working face. According to the comparative analysis of the sensitive indicators of the prominent prediction before and after the water injection on the coal seam, the elimination effect was obtained. The results showed that after the coalbed water injection, the maximum predictive sensitivity index of drilling desorption index $\mathrm{K} 1$ value, the maximum cuttings amount Smax and the drilling desorption index $\Delta \mathrm{h}_{2}$ maximum reduction were $50 \%, 30 \%$ and $20 \%$, respectively, and achieved a good elimination effect.
\end{abstract}

\section{Introduction}

As the level of mining extends deeper, the geological conditions become more and more complex, and the in-situ stress and gas pressure increase, which increases the possibility of coal and gas outburst accidents. The "Protection of Coal and Gas Outburst Regulations" requires that the outbreak prevention work adhere to the principles of regional anti-outburst measures and partial anti-outburst measures. After the implementation of regional outbreak prevention measures, the search for a cost-effective and effective elimination method has become the focus of domestic and foreign 
scholars [1-3]. Coal seam water injection is a kind of local anti-outburst measures with simple operation and low cost. Its core technology is to grasp the scope of the pores and water injection. Based on the above analysis, this paper takes the outburst prevention work of 1302 working face of Weijiadi coal mine as an example to carry out the research on the outburst water injection outburst prevention technology, and analyzes the effectiveness of the technology through the field

\section{Coal Bed Water Injection Mechanism}

The coal mine water flooding outburst mechanism mainly has the following aspects: (1) The process of water injection in the coal seam drives the free gas in the cracked channel to be driven out. At the same time, the adsorption of water on the coal body also increases the desorption of gas in the coal gas, thereby making gas more effective. It facilitates drainage and releases gas expansion energy. (2) The water injection in the coal seam will change the pore structure in the coal body ahead of the working face, so that the stress concentration area inside the coal seam will move to the deep, leaving a certain safe length for the pressure relief zone in front of the working face. (3) Water injection in the coal seam will increase the water content of the coal body, increase the plasticity of the coal body, greatly reduce the damage of the gas expansion to the coal body, and change the mechanical properties of the coal body, thereby reducing the incidence of coal and gas outburst accidents.

\section{Overview of Workface}

The current production capacity of the Weijiadi coal mine is $0.3 \mathrm{Mt} / \mathrm{a}$. It is a coal and gas outburst mine. There have been 11 gas dynamic phenomena. The gas content in the coal seam is 9.22 to $10.17 \mathrm{~m}^{3} / \mathrm{t}$, and the coal bed permeability coefficient is $0.213 \sim 0.7 \mathrm{~m}^{2} / \mathrm{MPa}^{2} \cdot \mathrm{d}, 100 \mathrm{~m}$ gas emission from boreholes is $0.152 \sim 0.278 \mathrm{~m}^{3} / \mathrm{min}$, gas flow attenuation coefficient from $100 \mathrm{~m}$ holes is $0.032 \sim 0.053 \mathrm{~d}^{-1}$, coal seam is soft and air permeability is poor. The 1302 working face is located in the west mining area of the mine, with a mining length of $1650 \mathrm{~m}$, an inclination length of $200 \mathrm{~m}$, an average coal seam thickness of $8 \mathrm{~m}$, a gas content of $9.17 \mathrm{~m}^{3} / \mathrm{t}$, a maximum gas pressure of $1.88 \mathrm{MPa}$, and a coal seam hardness coefficient of 0.5-1.0. During the tunnel excavation, cascading water injection drilling holes are arranged on both sides of the transportation trough and return air trough and in front of the working face.

\section{Water Injection Drilling Arrangement and Effects}

\subsection{Design of Injection Drilling Arrangement}

In order to ensure the effectiveness of the local outburst prevention measures during the mining of the 1302 working face, the two-slot long hole hydrostatic water injection and the cut-off short hole dynamic pressure water injection were used. The first type of water injection program is to perform long-borehole hydrostatic water injection under the return air trough along the 1302 working face, the hole diameter is $75 \mathrm{~mm}$, the hole length is $20 \mathrm{~m}$, the drilling distance is $10 \mathrm{~m}$, and the number of holes is not less than $8 \mathrm{~m}$. Short-hole dynamic pressure water injection in the cut-out, aperture $50 \mathrm{~mm}$, hole length $8 \mathrm{~m}$, drilling spacing $10 \mathrm{~m}$, mainly in the implementation of maintenance classes, to enhance the plasticity of the coal body, and the coal body stress to the deep transfer. The specific water injection wetting radius is the main basis for drilling holes. Many scholars [4-6] have simulated the drilling wetting radius of different geological conditions, and have played a guiding role in the implementation of drilling on site. According to the field survey and experience of the Weijiadi coal mine, the wet drainage radius of the water injection hole is about $5 \mathrm{~m}$, the wet radius of the water 
injection hole is greater than $5 \mathrm{~m}$, the sealing hole is $4-6 \mathrm{~m}$, the water injection pressure is $13-15 \mathrm{MPa}$, and the water injection pressure is obtained mainly from the effluent of the coal wall. A drop of 30\% depends on stopping the water injection. Long hole static pressure water injection shown in Figure 1, short hole dynamic pressure water injection shown in Figure 2.

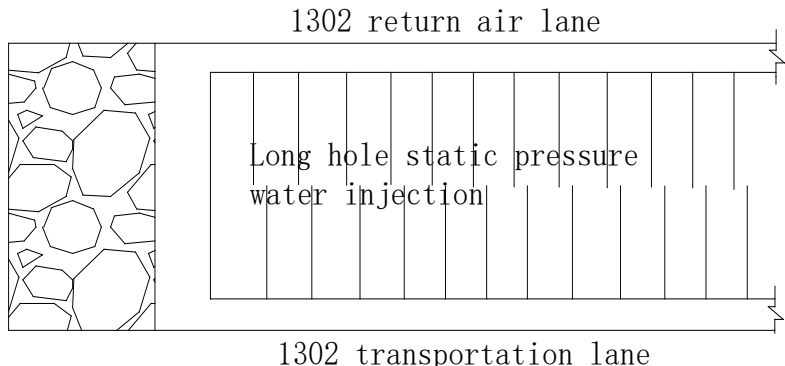

Fig.1 Long hole static pressure injection

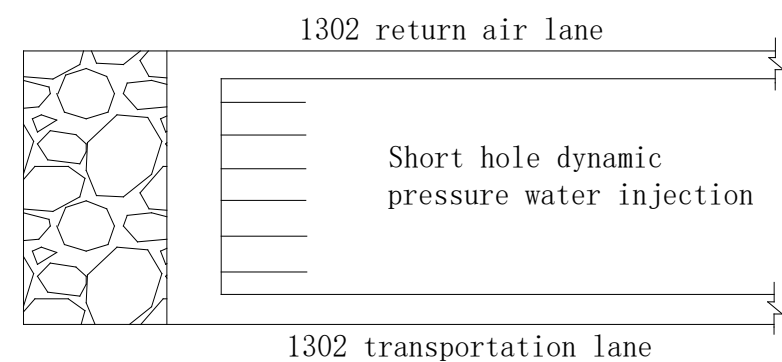

Fig.2 Short-hole dynamic pressure injection

\subsection{Determination of Water Injection Parameters}

\subsubsection{Water injection pressure}

Water injection pressure and water injection volume are the key to water burst prevention in coal seams. If the water injection pressure is too small, it will not change the changes in coal cracks and pore structure, and it will not be able to depressurize the coal and discharge gas; however, if the water injection pressure being too large may induce coal and gas outbursts. Two-slot hydrostatic water injection is mainly for the purpose of moistening the coal body and increasing the plasticity of the coal body. The water injection pressure is generally not less than $2 \mathrm{MPa}$. However, the short-hole high-pressure water injection in the working face is mainly to change the internal mechanical properties of the coal body, so that the concentrated stress in front of the coal body is transferred to the deep, and the pressure is generally at least $10 \mathrm{MPa}$.

\subsubsection{Sealing hole length and water injection time}

When two slots are used for hydrostatic water injection with long holes, a special sealer is used to seal the holes, and the length of the seal hole is $6 \mathrm{~m}$. During the water injection process, the water injection pressure and flow rate are measured through the water meter. When high-pressure water injection is performed on the short-hole drilled hole in the working face, the special hole sealer is used to seal the hole. The length of the hole to be sealed is $4 \mathrm{~m}$. In order to transfer the stress concentration zone to the deep part of the coal body, the early water injection pressure shall not be less than $10 \mathrm{MPa}$, and the post injection pressure shall be $6 \mathrm{MPa}$. During the water injection process, flow and pressure measurements should be made through the water meter. Short-hole high-pressure water injection time is generally about 2 hours. The water injection for the two-path hydrostatic tank is generally an intermittent water injection and lasts for about one week. It is determined according to the effect of water injection drilling, and the coal wall water outlet is over.

\subsection{Anti-outburst effect analysis}

After implementation of hydrostatic water injection with long hole in the trough and hydrodynamic water injection with short cut hole, the maximum drill cuttings Smax, the desorption index dh2, and the desorption index K1 of the drill cuttings were measured. Coal seam water injection 
outburst effect, as shown in Figure $3 \sim$ Figure 4.
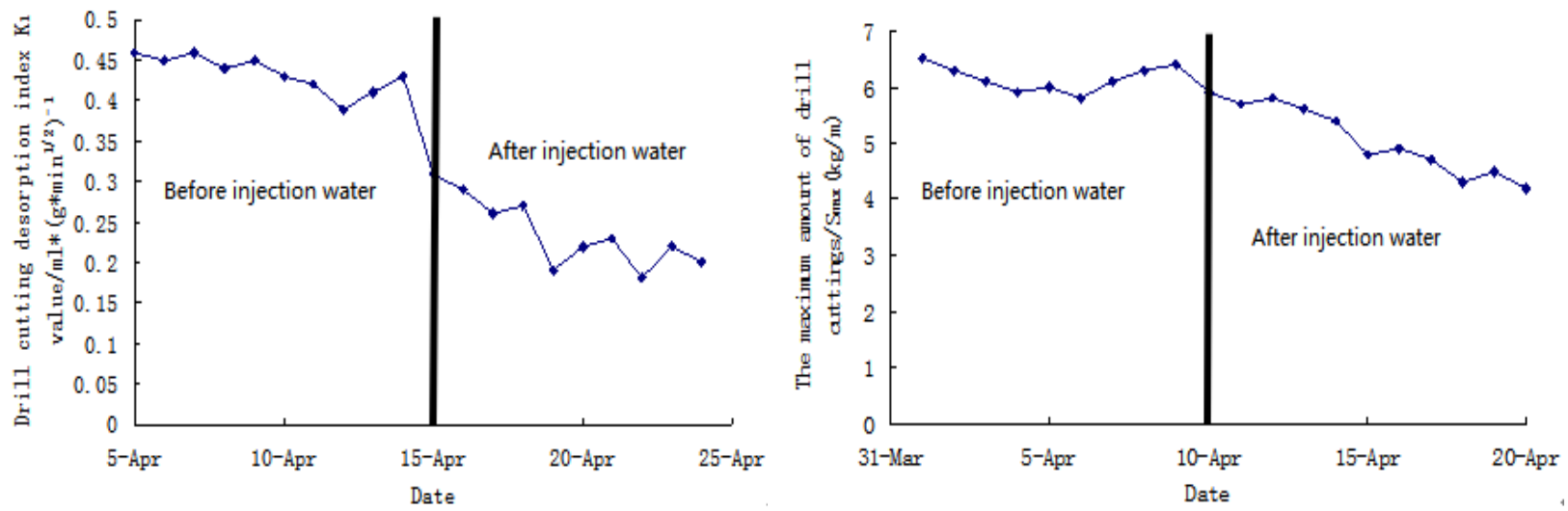

Fig.3 The change of $\mathrm{K}_{1}$ and Smax value of drill cuttings before and after water injection

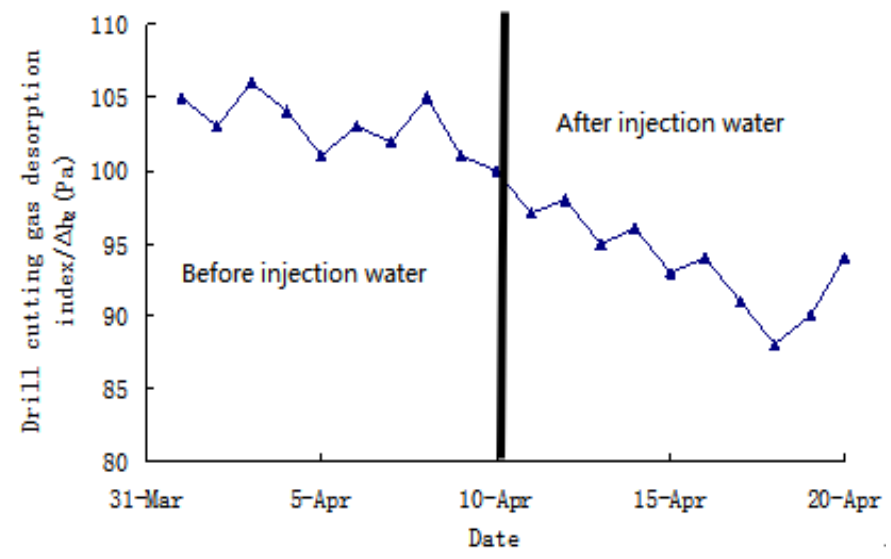

Fig. 4 The change of drill gas desorption index $\Delta \mathrm{h}_{2}$ before and after water injection

According to Figure 3, the desorption index $\mathrm{K}_{1}$ and Smax value of drill cuttings after water injection at the working face is respectively 0.2 and 4.2 at the lowest, and the maximum drop is respectively 50\% and 30\%; Fig. 4 shows that after the water injection, the value of $\Delta \mathrm{h}_{2}$ desorption index of drill cuttings is reduced to 88 at the lowest and the maximum drop is $20 \%$. Through coal seam water injection, the free gas in the coal seam is expelled and released, and some adsorbed gasses are also desorbed. The content of gas in the coal seam is greatly reduced, and gas outburst accidents are effectively controlled.

\section{Conclusion}

(1) Based on the analysis of coal seam water injection outburst and actual conditions on the site, a coal mine water injection outburst program combining long borehole hydrostatic injection and short borehole hydrodynamic pressure injection was proposed, and the criticality of high pressure water injection was determined based on the energy principle.

(2) After field application, after the water injection in the coal seam, the maximum predictive sensitivity index $\mathrm{K}_{1}$ value of the desorption index of drill cuttings, the maximum amount of drill cuttings Smax, and the maximum reduction of drill desorption index $\Delta \mathrm{h}_{2}$ are $50 \%, 30 \%$, and $20 \%$, respectively, thus reduces the possibility of accidents and ensures safe mining. 


\section{Acknowledgments}

This work was financially supported by 2018 Gansu Provincial Safety Science and Technology Project[GAJ00011] and Longdong University Youth Science and Technology Innovation Project[XYZK1610] fund.

\section{References}

[1] Zhang Minbo, Lyu Dongnan, Bu Qingxiang. Study and Application of Coalbed Water Injection Anti-Outburst Technology in 172405 Working Face of Dashucun Coal Mine[J]. Coal Technology,2018,37(04):134-136.

[2] Li Xiangdong, Liu Jianxi. Measurement on Outburst Prevention Effective Influence Radius of Water Injection with Shallow Borehole in Seam[J]. Coal Science and Technology,2012,40(1):54-56.

[3] Xiao Zhiguo, Wang Zhaofeng. Status and Progress of Studies on Mechanism of Preventing Coal and Gas Outburst by Coal Seam Infusion[J]. China Safety Science Journal,2009,19(10):150-158.

[4] Liu Mingju, Pan Hui, Li Yongjun, et.al. Research and app lication of coal and gas outburst control measure based on hydraulic extrusion in roadway[J]. JOURNAL OF CHINA COAL SOCIETY,2007,32(2):168-171.

[5] Hu Guangwei, Wu Yongzheng. Application of Water Injection into Coal-seam in Preventing Coal and Methane Burst in Coal Roadway[J]. Coal mining Technology,2012,17(1):91-92.

[6] Li Zhiqiang, Tang Xu, Wang Zhaofeng. Regional Outburst Prevention Test by Coal Seam Infusion Humidification and Permeation Fluid Mechanics Numerical Solution of Parameter Optimization[J]. Coal mine safety,2012,43(9):10-13. 